\title{
LSD1 inhibition attenuates androgen receptor V7 splice variant activation in castration resistant prostate cancer models
}

\author{
Sergio Regufe da Mota', Sarah Bailey ${ }^{1}$, Rosemary A. Strivens ${ }^{1}$, Annette L. Hayden ${ }^{1}$, Leon R. Douglas², \\ Patrick J. Duriez ${ }^{2}$, M. Teresa Borrello ${ }^{3}$, Hanae Benelkebir ${ }^{3}$, A. Ganesan³ , Graham Packham \\ and Simon J. Crabb ${ }^{1^{*}}$ (D)
}

\begin{abstract}
Background: Castrate resistant prostate cancer (CRPC) is often driven by constitutively active forms of the androgen receptor such as the V7 splice variant (AR-V7) and commonly becomes resistant to established hormonal therapy strategies such as enzalutamide as a result. The lysine demethylase LSD1 is a co-activator of the wild type androgen receptor and a potential therapeutic target in hormone sensitive prostate cancer. We evaluated whether LSD1 could also be therapeutically targeted in CRPC models driven by AR-V7.

Methods: We utilised cell line models of castrate resistant prostate cancer through over expression of AR-V7 to test the impact of chemical LSD1 inhibition on AR activation. We validated findings through depletion of LSD1 expression and in prostate cancer cell lines that express AR-V7.

Results: Chemical inhibition of LSD1 resulted in reduced activation of the androgen receptor through both the wild type and its AR-V7 splice variant forms. This was confirmed and validated in luciferase reporter assays, in LNCaP and 22Rv1 prostate cancer cell lines and in LSD1 depletion experiments.
\end{abstract}

Conclusion: LSD1 contributes to activation of both the wild type and V7 splice variant forms of the androgen receptor and can be therapeutically targeted in models of CRPC. Further development of this approach is warranted.

Keywords: Androgen receptor, LSD1, Prostate cancer, Castration resistance, Enzalutamide, AR-V7 splice variant

\section{Background}

Over 40,000 men are diagnosed with prostate cancer, and over 10,000 die from advanced metastatic disease, annually in the UK. Initial treatment of metastatic disease is reliant on inhibiting androgen receptor (AR) signalling by systemic androgen deprivation therapy (ADT). Although almost all patients respond to ADT, disease progression, to a clinical phenotype termed castration resistant prostate cancer (CRPC), occurs in virtually all patients. Metastatic CRPC is almost uniformly lethal within a median of

\footnotetext{
*Correspondence: S.J.Crabb@southampton.ac.uk

${ }^{1}$ Cancer Sciences Unit and Cancer Research UK Centre, University of Southampton, Southampton General Hospital, Somers Cancer Research Building, Mailpoint 824, Southampton SO16 6YD, UK Full list of author information is available at the end of the article
}

2-3 years and is commonly accompanied by significant symptomatic and healthcare burden [1].

Treatment options after transition to CRPC have developed significantly in the last few years. Approaches that are established to extend survival include further hormonal intervention with either the new generation $\mathrm{AR}$ antagonist enzalutamide or the CYP17A1 androgen synthesis inhibitor abiraterone acetate [2-5]. These therapeutic advances reflect the fact that, despite resistance to systemic androgen suppression, CRPC usually remains critically dependent on AR signalling.

As a conventional nuclear steroid hormone receptor transcription factor, AR activation involves ligand binding (e.g., testosterone, dihydro-testosterone), phosphorylation and homo-dimerisation, nuclear translocation, 
formation of co-regulator complex interactions with chromatin modifiers, androgen response element (ARE) sequence binding within target gene promoters and AR target gene expression and suppression. Non-genomic/ non-ARE mediated effects also occur through AR activation [6].

Androgen deprivation therapy failure and transition to CRPC occurs through multiple mechanisms including expression of constitutively active AR point mutants and splice variants, AR co-regulator expression changes, AR expression change, altered AR ligand sensitivity/promiscuity and signalling pathway crosstalk (e.g., with PI3K/ AKT or IGFR). Critically we have no current routinely available means within the clinic to detect resistance mechanisms to either initial ADT or subsequent therapies [6-12].

Intense interest currently surrounds the $\mathrm{V} 7$ splice variant of the AR which lacks a ligand (or enzalutamide) binding domain leaving a constitutively active N-terminal. AR-V7 expression represents a relatively common cause of transition to a CRPC phenotype and a cause of resistance to enzalutamide or abiraterone. Recent data found that AR-V7 detection in circulating tumour cells was possible in $19-39 \%$ of CRPC patients who were naive to new generation hormonal agents. AR-V7 expression was associated with almost complete loss of biochemical prostate specific antigen (PSA) response to enzalutamide or abiraterone and reduced median survival $[7,8]$. Subsequent data have emerged to indicate that AR-V7 forms part of a wider spectrum of activating AR structural derangements, typically splice variants and point mutants, that drive some CRPC and with the hope that detection might allow for treatment resistance/sensitivity biomarkers to be developed [13].

Co-regulators of AR transcriptional activation include epigenetic mediators that induce chromatin remodelling at AR response element sites [14, 15]. A key example is the flavin-dependent nuclear amine oxidase LSD1 [16]. LSD1 is a lysine demethylase which, dependant on context, can repress or activate transcription. The best characterised LSD1 substrates for demethylation are mono- and di-methylation at lysine 4 of histone $\mathrm{H} 3$ (H3K4me1, H3K4me2) which are transcriptionally activating. LSD1 is a component of the CoREST transcriptional co-repressor complex that also contains CtBP and histone deacetylase (HDAC) 1 and HDAC2. Within this complex, LSD1 demethylates H3K4me1 and H3K4me2, facilitating gene silencing in concert with HDAC activity $[16,17]$. By contrast, LSD1 associates with the AR in human prostate cells to remove mono- and di-methyl marks at histone $\mathrm{H} 3$ lysine 9 (H3K9me1, H3K9me2) at ARE sites [14, 15]. In contrast to H3K4 methylation, H3K9 methylation is transcriptionally repressive and the
AR co-regulator function of LSD1 facilitates AR dependent transcriptional activation [14, 15]. LSD1 functions in concert with the histone demethylase lysine (K)-specific demethylase $4 \mathrm{C}$, which demethylates $\mathrm{H} 3 \mathrm{~K} 9 \mathrm{me} 3$ within AR activating complexes to promote AR mediated transcription also $[14,15]$. Cellular epigenetic status in favour of H3K9 demethylation by LSD1 over H3K4 demethylation is not fully elucidated but determined in part through protein kinase $\mathrm{C}$ beta I phosphorylation of histone H3 threonine 6 [18]. Alternative splicing of LSD1 may also impact on substrate specificities in some contexts [19].

LSD1 expression is increased in prostate cancer compared with benign prostate and its expression correlates with higher Gleason score, risk of relapse and distant metastases, and reduced survival post prostatectomy $[20,21]$. Histone marks consistent with LSD1 activity are altered in prostate cancer versus normal tissue (reduced H3K4me1, H3K9me2 and H3K9me3 marks) [22]. Taken together these data provide a rationale to develop LSD1 inhibition as a strategy to attenuate AR signalling.

We and others have shown that chemical inhibition of LSD1 inhibits cell proliferation and AR signalling in prostate cancer cells $[14,15,23-25]$. Validation of LSD1 as a potential therapeutic target in prostate cancer has been undertaken through LSD1 siRNA depletion experiments [14]. We hypothesised that LSD1 inhibition would also attenuate AR activation in models of CRPC driven by the AR-V7 splice variant.

\section{Methods}

\section{Reagents and cell lines}

Cell lines were maintained in Dulbecco's Modified Eagle's Medium (HEK293 cells; Sigma) or Roswell Park Memorial Institute (RPMI) medium (LNCaP cells; Sigma) supplemented with $10 \%$ fetal bovine serum (FBS) with $4 \mathrm{mM}$ (HEK293) or $2 \mathrm{mM}$ (LNCaP) L-glutamine and $1 \mathrm{mM}$ pyruvate. For experiments, LNCaP cells were incubated for $24 \mathrm{~h}$ and then media was changed to RPMI-1640 (phenol free; Life Technologies) supplemented, for the remainder of the experiment, with 10\% charcoal stripped FBS (Life Technologies). Dihydrotestosterone (DHT) and $5 \alpha$-Androstan-17 $\beta$-ol-3-one were from Sigma-Aldrich; LSD1 inhibitors LSD1-C76 and HCI-2509 were from Xcess Biosciences; enzalutamide and apalutamide were from Selleckchem. Chemical inhibitors of LSD1 were synthesised, and a separate publication will describe full details of the preparation.

\section{In vitro LSD1 inhibition assay}

$\mathrm{IC}_{50}$ values for LSD1 activity after chemical inhibition were measured as previously described [25]. Briefly, this involves incubation of the purified enzyme with an 
H3K4me2 peptide substrate and measurement of byproduct $\mathrm{H}_{2} \mathrm{O}_{2}$ using AmplexRed ${ }^{\circledR}$ (Invitrogen).

\section{Cell proliferation assays}

Cell proliferation assays were performed by incubating cells in 96 well plates in RPMI complete medium. After $24 \mathrm{~h}$, different drugs or a DMSO control were added and analysis of proliferation was determined after $72 \mathrm{~h}$ using the CellTiter-Glo ${ }^{\circledR} 2.0$ Assay (Promega) according to the manufacturer instructions. Luminescence was measured using a Varioskan Flash Multimode Reader (Thermo Scientific).

\section{Immunoblotting}

Cells were harvested and lysed by resuspension in protein sample buffer. DNA from samples was fragmented by sonication. Total protein from each sample was separated using the Laemmli method [26]. After blocking, the membranes were immunoblotted overnight at $4{ }^{\circ} \mathrm{C}$ with primary antibodies to LSD1, PSA/KLK3, androgen receptor and cleaved PARP (Cell Signalling) and $\beta$-Actin (Sigma-Aldrich) as previously described [27].

\section{CRISPR experiment}

LSD1 knockout was undertaken in HEK293 cells according to the protocol from Zhang et al. [28]. Briefly, HEK293 cells were transfected with the Cas9 expressing vector $\mathrm{pSpCas} 9(\mathrm{BB})-2 \mathrm{~A}-\mathrm{GFP}$ (Addgene) with a guide sequence targeting the ATG for KDM1A (LSD1). For the selection of the guide sequence oligonucleotide we used an online tool for CRISPR design (http://crispr.mit.edu/). Guide sequence oligonucleotides were, top $5^{\prime}$ caccgTGT GTTTTGATCGGGTGTTC $3^{\prime}$ and bottom $5^{\prime}$ aacGAA CACCCGATCAAAACACAC $3^{\prime}$.

\section{Luciferase reporter assays}

Luciferase assays were performed using a vector (pARELuc) with the firefly luciferase gene under the control of the androgen receptor response element (ARE) in HEK293 cells co-transfected with peAR-Wt and peARV7 plasmids and with a renilla luciferase vector used as a transfection efficiency control as previously described $[29,30]$. Briefly, HEK293 cells were transfected with Fugene HD (Promega) using a 9:1 ratio of AR:ARE vectors $(1 \mu \mathrm{g}$ DNA) along with $5 \mathrm{ng}$ of a renilla control vector. After $30 \mathrm{~h}$, cells were treated with chemical inhibitors according to the experimental requirements and then firefly and renilla luciferase activity were measured using the Dual-Luciferase ${ }^{\circledR}$ Reporter Assay System (Promega) in a Varioskan ${ }^{\mathrm{TM}}$ Flash Multimode Reader (Thermo Scientific). All results show firefly luciferase activity normalised to renilla luciferase activity to control for transfection efficiency.

\section{Chromatin immunoprecipitation (CHIP) assay}

CHIP assays were performed using the ChIP-IT ${ }^{\circledR}$ High Sensitivity kit (Active Motif) according to the manufacturer's instructions. Immunoprecipitation of the chromatin bound DNA was performed using the following antibodies from Active Motif: Histone H3 K9me3, Histone H3, Histone H3 K9me2, Histone H3K9me1. The ChIP-IT $^{\circledR}$ Control Kit, Human was used with these assays as a control.

\section{Quantitative real-time PCR}

Total mRNA extraction was performed using the RNAeasy kit (Qiagen) according to the manufacturer's instructions. Contaminating DNA was digested using RQ1 DNAse (Promega). Synthesis of cDNA was performed using M-MLV Reverse Transcriptase (Promega) according to the manufacturer's instructions. For qRTPCR we used the TaqMan ${ }^{\circledR}$ Universal PCR Master Mix, No AmpErase ${ }^{\circledR}$ UNG (ThermoFischer Scientific) and TaqMan ${ }^{\circledR}$ Gene Expression Assays probes for KLK3 (PSA) and for the reference gene GAPDH. Assays were performed in an Applied Biosystems 7500 Real Time PCR System. Quantification of mRNA expression levels was performed using the $2^{-\Delta \Delta C(T)}$ method as described [31].

\section{Results}

Chemical inhibition of LSD1 inhibits activity of the androgen receptor

We first validated the impact of LSD1 chemical inhibition on wild type androgen receptor transcriptional activation. We investigated the effects of the LSD1 inhibitor tranylcypromine (1, Additional file 1: Figure S1) which is currently under investigation in clinical trials for acute myeloid leukaemia (http://www.clini caltrials.gov) and a set of five second-generation tranylcypromine analogues (2-6, Additional file 1: Figure S1) with improved target affinity in biochemical enzyme assays. Each of these compounds were shown to inhibit both in vitro activity of LSD1 and cell proliferation in LNCaP prostate cancer cells (Table 1, Additional file 1: Figure S2, Figure S3) but with many fold increase in potency over the tranylcypromine base compound. LSD1 chemical inhibition reversed DHT induced loss of histone $\mathrm{H} 3 \mathrm{~K} 9$ mono-methylation in LNCaP prostate cancer cells in CHIP assays (Fig. 1). We also demonstrated reduction of AR and LSD1 protein expression and of the AR transcriptional target PSA in LNCaP cells, together with evidence of PARP cleavage in response to LSD1 inhibition (Fig. 2). 
Table $1 I_{50}$ and $L_{50}$ values for LSD1 inhibitor compounds for in vitro LSD1 inhibition assays and LNCaP prostate cancer cell proliferation assays respectively

\begin{tabular}{|c|c|c|c|c|}
\hline \multirow[t]{2}{*}{ Compound } & \multicolumn{2}{|c|}{ LSD1 inhibition } & \multicolumn{2}{|c|}{ Cell proliferation } \\
\hline & $\begin{array}{l}\mathrm{IC}_{50} \text { mean } \\
(\mathrm{nM})\end{array}$ & $\mathrm{SD}(\mathrm{nM})$ & $\begin{array}{l}\mathrm{LD}_{50} \text { mean } \\
(\mu \mathrm{M})\end{array}$ & $\mathrm{SD}(\mu \mathrm{M})$ \\
\hline $\begin{array}{l}\text { Tranylcy- } \\
\text { promine (1) }\end{array}$ & $57,980.0$ & 5922.9 & 2235.0 & 173.6 \\
\hline 2 & 4389.0 & 157.9 & 136.3 & 1.7 \\
\hline 3 & 1520.5 & 890.3 & 605.9 & 90.4 \\
\hline 4 & 259.3 & 22.8 & 224.9 & 27.9 \\
\hline 5 & 269.4 & 35.7 & 712.4 & 48.5 \\
\hline 6 & 221.6 & 26.7 & 183.9 & 19.6 \\
\hline LSD1-C76 & 527.0 & 9.0 & 85.1 & 9.5 \\
\hline
\end{tabular}

Data represent mean values \pm standard deviation (SD), as indicated, for a minimum of three experiments in each case

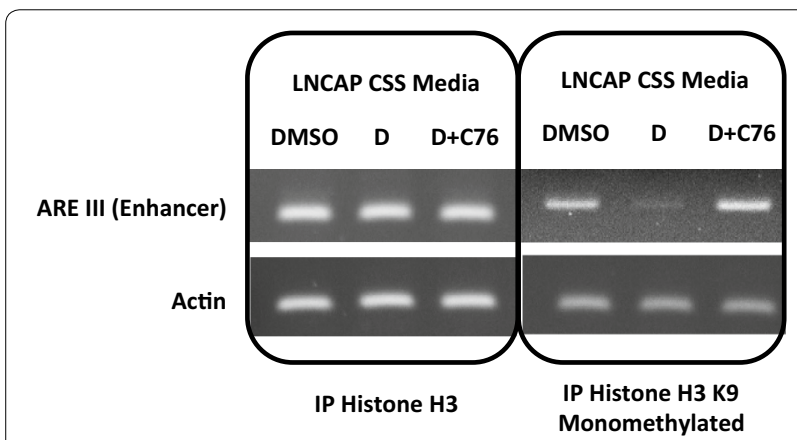

Fig. 1 CHIP analysis of LNCaP cells treated with the LSD1 inhibitor LSD1-C76. LNCaP cells were incubated in media with charcoal stripped serum (CSS) for $24 \mathrm{~h}$ prior to addition of dihydrotestosterone $(\mathrm{D}, 1 \mathrm{nM}) \pm \mathrm{LSD} 1-\mathrm{C} 76(\mathrm{C} 76,250 \mu \mathrm{M})$ for $24 \mathrm{~h}$. CHIP was performed using histone $\mathrm{H} 3$ and histone $\mathrm{H} 3 \mathrm{~K} 9$ mono-methylated antibodies.

Precipitated chromatin was amplified using primers flanking the enhancer region (ARE III) of the PSA gene or actin gene promoter [14]. DMSO dimethyl sulfoxide solvent control

\section{LSD1 chemical inhibition attenuates AR-V7 splice variant activation}

AR-V7 and other AR splice variant forms are strongly implicated in hormonal therapy resistance and may contribute to some forms of castration resistant prostate cancer [7, 8]. To explore the impact of LSD1 on AR-V7 activity, we initially utilised a luciferase reporter assay system to measure ARE activation in HEK-293 cells through co-transfection of the AR with either wild type (WT) or V7 splice variant forms. Within this model system, we first confirmed that AR-WT activation is inhibited by the established AR antagonists enzalutamide $[2,5]$ and apalutamide [32, 33] but that the AR-V7 splice variant, by virtue of constitutive activation and loss of the binding site for either drug, demonstrates resistance to these agents (Additional file 1: Figure S4). Having confirmed the anticipated functional characteristics of this system we then demonstrated that partial inhibition of AR-V7 constitutive activation is seen upon chemical inhibition of LSD1 (Fig. 3).

\section{LSD1 depletion attenuates both AR-WT and AR splice variant activation}

To validate evidence that LSD1 contributes to the activity of AR splice variant forms we undertook experiments to deplete LSD1 expression in HEK-293 cells followed by co-transfection of either AR-WT or splice variant forms in ARE luciferase reporter experiments. Depletion of LSD1 (by CRISPR; Additional file 1: Figure S5) resulted in partial inhibition of AR activity in this model for both the AR-WT and the AR-V7 splice variant and also for a further, constitutively active, AR C-terminal truncated splice variant Q640X (Fig. 4) [29].

We next turned to a prostate cancer cell line model for AR-V7 activation through transfection of an AR-WT or AR-V7 expression construct into the LNCaP cell line. In this model, chemical inhibition of LSD1 resulted in depletion of AR-WT and LSD1, although not AR-V7 in this model, and also the AR transcriptional target PSA (Fig. 5).

\section{LSD1 inhibition depletes AR activity in prostate cancer cells expression endogenous AR-V7}

Finally we utilised the $22 \mathrm{Rv} 1$ prostate cancer cell line to represent a CRPC model with high AR activity and endogenous expression of both the AR full length and V7 forms [34]. In 22Rv1 cells we showed reduced expression of both AR-WT, AR-V7 and LSD1 and also depletion of PSA RNA levels on exposure to chemical inhibition of LSD1 (Fig. 6).

\section{Discussion}

Castration resistant prostate cancer is a challenging disease. Although there have been significant advances in new therapeutic options, including hormonal therapy, chemotherapy, systemic radioisotope therapy and immunotherapy, the disease remains highly lethal $[2-5,33,35-$ 37]. In fact, CRPC normally remains critically dependent on AR signalling, even following acquired resistance to hormonal interventions such as enzalutamide, apalutamide and abiraterone $[7,8]$. The mechanisms underlying castration resistance commonly relate to the AR itself through receptor amplification, activating point mutations and constitutively active truncating splice variants of which the AR-V7 splice variant is a key example. One strategy to develop novel approaches to CRPC is 
a

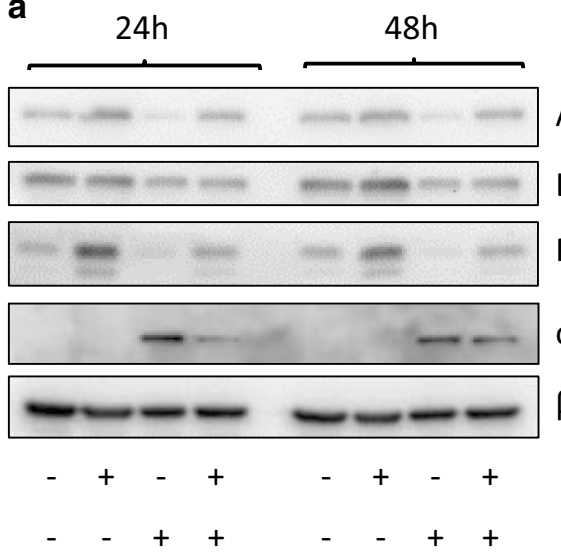

b

$A R$

LSD1

PSA

CPARP

$\beta$-Actin

DHT

LSD1-C76

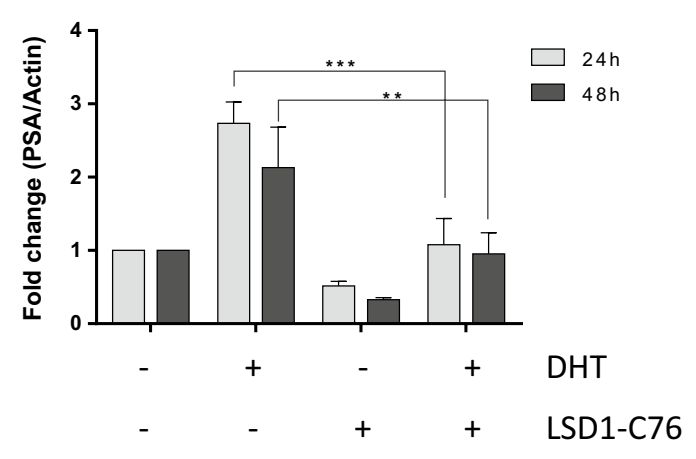

d

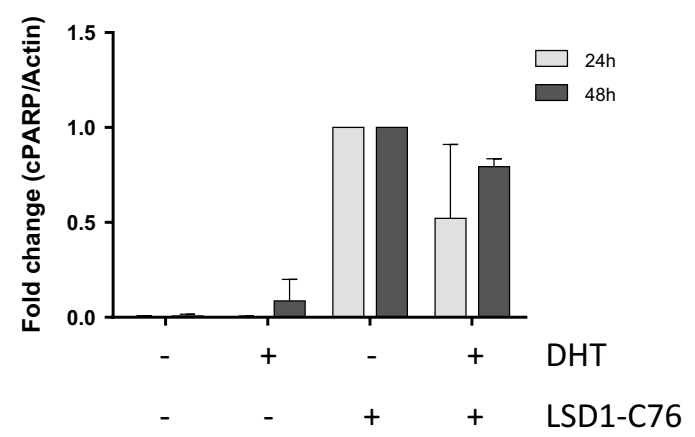

Fig. 2 Chemical inhibition of LSD1 reduces AR, PSA and LSD1 expression and induces PARP cleavage. a Western blot analysis of the indicated targets in LNCaP prostate cancer cells, grown in charcoal stripped media for $24 \mathrm{~h}$ before exposure to dihydrotestosterone (DHT, $1 \mathrm{nM}$ ) or LSD1-C76 $(250 \mu \mathrm{M})$ for 24 or $48 \mathrm{~h}$ as indicated. b-e Quantification of PSA (b), LSD1 (c), CPARP (d) and AR-WT (e) protein levels by densitometry analysis and normalized to $\beta$-actin. Western blots are representative of two independent experiments. P values were derived using 2 Way ANOVA multiple comparisons test. CPARP, cleaved PARP; ${ }^{* *}$ and ${ }^{* * *} \mathrm{P}<0.005$ and $\mathrm{P}<0.001$ respectively

therefore to target abnormal forms of the AR, including constitutively active splice variants, of which AR-V7 is the most frequently relevant form $[7,8]$.

Epigenetic therapeutic approaches remain experimental in prostate cancer. However, evidence exists for a variety of epigenetic mechanisms driving prostate cancer development, disease progression and aggressiveness, and transition to a CRPC phenotype. Relevant epigenetic aberrations include silencing of tumour suppressor genes by promoter hypermethylation, aberrant expression of histone modulating proteins, and DNA hypomethylation [38]. Potential approaches to target these are therefore of interest. DNA methyltransferase inhibition and histone deacetylase inhibition have received the most attention although translation through to clinical benefit remains to be established, perhaps partly due to a lack of companion predictive biomarkers for these approaches [38]. LSD1 has been shown to attenuate wild type AR activity and drive progression of the disease to more advanced clinical states $[15,20-24,38]$. We therefore sought to test whether this would extend to an impact on the function of AR-V7 as a key driver of many cases of CRPC and hormonal therapy resistance $[7,8]$.

We have established, in a variety of models, that LSD1 inhibition will attenuate signalling through not just the WT form of the receptor but also the ligand independent constitutively active AR-V7 form. Evidence for our ability to target the receptor with chemical inhibition was validated through use of knockdown experiments to deplete LSD1 expression. In addition we have demonstrated this in both a HEK293 co-transfection model to facilitate isolation of this phenomenon to AR-V7 or AR-WT separately, as well as in prostate cancer cell line models for dual V7 and WT expression through either forced expression (LNCaP cells) or endogenous expression (22Rv1 cells). We therefore propose that the impact of LSD1 on the androgen receptor is likely not lost by transition to a castration resistant phenotype where this arises through AR-V7 activity and regardless of the WT/V7 co-expression status. This would 


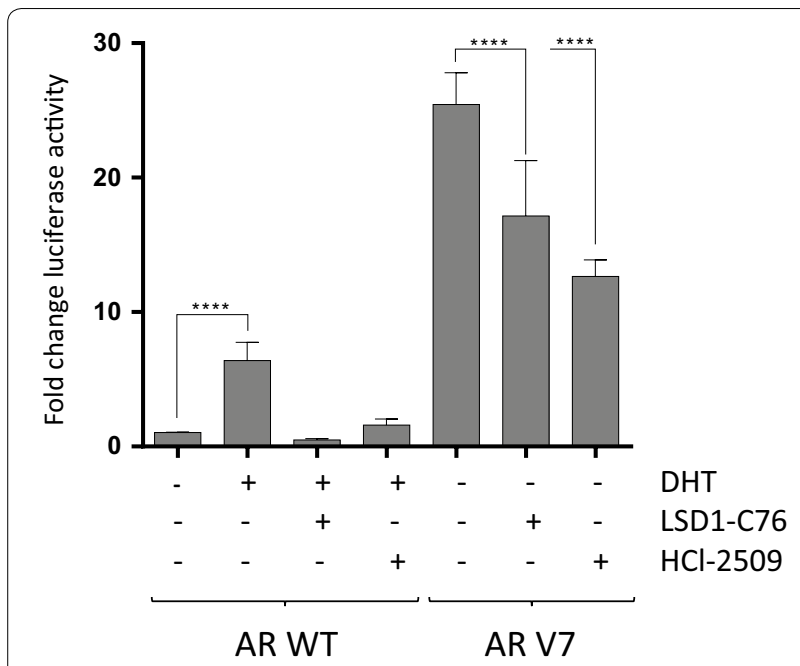

Fig. 3 LSD1 chemical inhibition depletes AR response element activation through the AR-V7 splice variant. Luciferase reporter assay of AR response element (ARE) promotor activation in HEK293 cells co-transfected, $24 \mathrm{~h}$ after seeding as indicated, with either AR-WT or AR-V7 expression vectors, and incubated $24 \mathrm{~h}$ later as indicated with

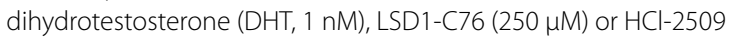

$(5 \mu \mathrm{M})$ or DMSO solvent control and then analysed at $18 \mathrm{~h}$. Samples were normalized against the AR-WT DMSO treated samples. Data are mean values \pm standard deviation from 4 separate experiments each with triplicate determinations. P values were derived using a two-way ANOVA for comparison followed by Tukey's multiple comparison post hoc tests. AR androgen receptor; WT wild type; ${ }^{* * * *} \mathrm{P}<0.0001$

imply that AR-V7 retains a requirement for complex formation with LSD1, for functional activation. Having established that AR-V7 driven prostate cancer remains susceptible to targeting of LSD1, at least in the model systems used here, it will be important to dissect the molecular interaction between chemical LSD1 inhibition and an LSD1:AR interaction. Proper understanding of the molecular basis for a therapeutic effect will be critical to facilitate exploitation of this strategy. In addition, we fully acknowledge that LSD1 inhibition might function as a therapeutic strategy through other mechanisms beyond targeting of AR-WT and AR-V7.

Our results would suggest broadly that depletion of LSD1 activity was able to reduce AR-V7 activation by about $50 \%$ in most of the experimental models that we utilised. This was seen in LSD1 knockdown models and so implies that this may be more than a simple 'drug potency' issue. It is likely that other epigenetic influences on AR activation remain relevant and thus combinatorial approaches may be required for optimal suppression of AR function [38]. To what degree a greater impact on AR signalling, either through the wild type or V7 splice variant forms of the AR will be required for therapeutic efficacy remains to be determined. Our work has shown that reduced LSD1 activity is effective in attenuating signalling through the AR Q640X splice variant in addition to AR-V7 suggesting that this experimental approach might be considered more widely than just 'AR-V7 positive' CRPC. CRPC driven through other AR activating mechanisms, such as activating point mutations, AR amplification, AR phosphorylation or AR methylation should be investigated also. a

AR WT

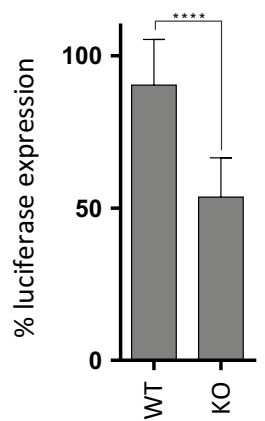

AR V7

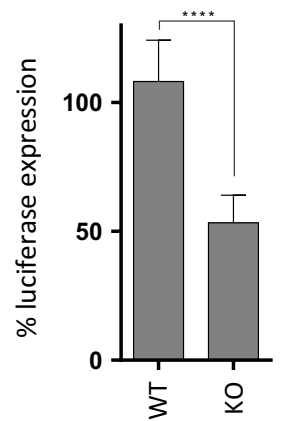

AR Q640X

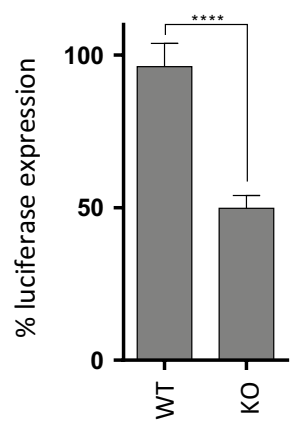

b WT KO

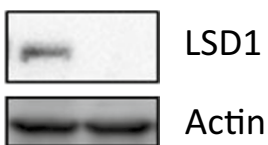

Fig. 4 AR-V7 splice variant activation is attenuated by LSD1 depletion. a Luciferase androgen response element (ARE) reporter assays in HEK293 cells with (KO) or without (C) stable depletion of LSD1 (by CRISPR) followed by transient co-transfection with an ARE luciferase reporter construct and either AR-WT, AR-V7 or AR Q640X expression vectors as indicated. In the cells transfected with AR-WT, dihydrotestosterone (1 nM) was added for $18 \mathrm{~h}$. Samples were normalized against LSD1 WT DMSO treated samples for the respective AR-WT of AR variant form transfected. Data are mean $\pm S D(n=3)$. P values were derived using a two-way ANOVA for comparison followed by Tukey's multiple comparison post hoc tests. (Controls without transfection of either the AR or an AR variant produced no ARE luciferase signal in these experiments). b Western blot of HEK293 cell LSD1 expression with (KO) or without (WT) stable depletion of LSD1. ***P $<0.0001$ 


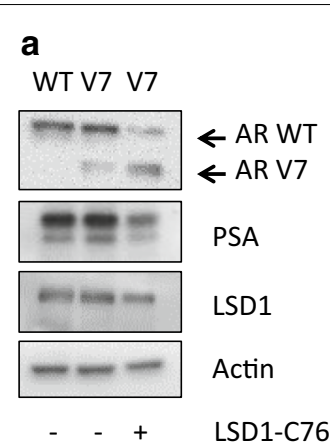

\section{b}

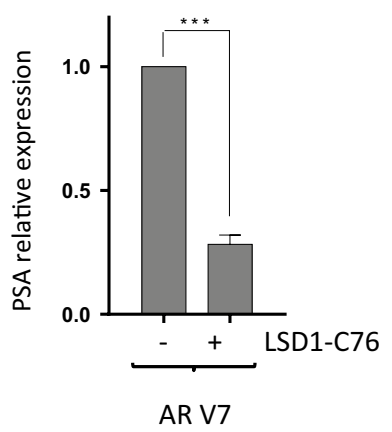

Fig. 5 Chemical inhibition of LSD1 reduces PSA expression driven by AR-V7. a Western blot analysis of AR, LSD1 and PSA expression in LNCaP cells transfected with either the AR-WT or the AR-V7 splice variant as indicated. LNCaP cells were incubated in CSS-media for $24 \mathrm{~h}$ prior to transfection and after $24 \mathrm{~h} \mathrm{LSD1-C76}(250 \mu \mathrm{M})$ or DMSO solvent control were added for $18 \mathrm{~h}$. b Quantification of PSA expression in three independent experiments. PSA levels were normalized against the DMSO treated samples. P values were derived using an unpaired t test with Welch's correction. ${ }^{* * *} \mathrm{P}<0.05$

\section{a}

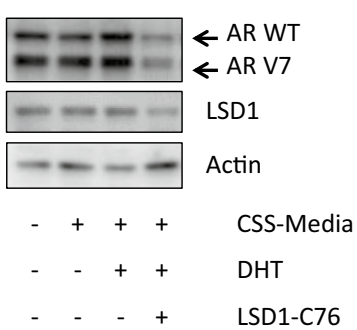

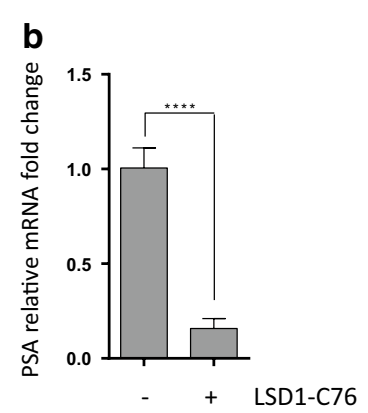

Fig. 6 Chemical inhibition of LSD1 depletes AR activity in an AR-V7 expressing 22Rv1 prostate cancer cells. 22Rv1 cells, expressing both endogenous AR-WT and V7 splice variants, were incubated in CSS-media for $24 \mathrm{~h}$ prior to adding dihydrotestosterone (DHT, $1 \mathrm{nM}$ ) and LSD1-C76 (250 $\mu \mathrm{M})$ for $18 \mathrm{~h}$ as indicated (or DMSO solvent control). a Western blot analysis of AR and LSD1 expression. b PSA mRNA expression determined by qPCR in three independent experiments. $P$ values were derived using an unpaired t test with Welch's correction. ${ }^{* * *} \mathrm{P}<0.05$

\section{Conclusions}

AR-V7 splice variant models of CRPC are amenable to therapeutic targeting through LSD1 inhibition. This raises the opportunity to develop this therapeutic strategy further.

\section{Additional file}

Additional file 1: Flgure S1. Figure S1 Molecular structure of the LSD1 inhibitors used in this work. Figure S2. In vitro LSD1 inhibition assay for the indicated compounds. Data points show percentage of LSD1 activity when compared with the DMSO treated sample for three separate experiments. Figure S3. Cell proliferation assays for the indicated compounds in LnCAP prostate cancer cells. Data points show percentage luminescence compared to DMSO solvent exposed control samples after $72 \mathrm{~h}$ for a minimum of three separate experiments in each case. Figure $\mathbf{S 4}$. Androgen response element (ARE) luciferase reporter assay, in response to androgen receptor (AR) antagonists, for the AR wild type (WT) or V7 splice variant forms. (A) Luciferase reporter assay of ARE promotor activation in HEK293 cells co-transfected, as indicated, with either ARWT or V7 expression vectors, and incubated as indicated with dihydrotestosterone (DHT; $1 \mathrm{nM})$, enzalutamide (10uM) or apalutamide (10uM). Data are mean values \pm standard deviation from four replicate determinations. P values were derived using a two-way ANOVA for comparison followed by Tukey's multiple comparison post hoc tests. (B) Western blot to confirm AR expression following transfection of either the WT or V7 or Q640X splice variant forms or an untransfected sample, as indicated, in HEK293 cells. ${ }^{* * *}, \mathrm{P}<0.0001$; ns, non-significant; NT, non-transfected. Figure $\mathbf{S 5}$. Western blot analysis of LSD1 expression for different clones obtained after the CRISPR experiment. (A) immunoblot for the N-terminus of human LSD1. (B) immunoblot for the C-terminus of human LSD1. Actin expression is shown as a protein loading control.

\section{Abbreviations}

ADT: androgen deprivation therapy; AR: androgen receptor; ARE: androgen response element; CHIP: chromatin immunoprecipitation; CRPC: castration resistant prostate cancer; $\mathrm{DHT}$ : dihydrotestosterone; HDAC: histone deacetylase; H3K4me1, H3K4me2: mono- and di-methylation respectively at lysine 4 of histone $\mathrm{H3}$; H3K9me1, H3K9me2: mono- and di-methylation respectively at histone H3 lysine 9; PSA: prostate specific antigen; RPMI: Roswell Park Memorial Institute; V7:V7 splice variant; WT: wild type.

\section{Authors' contributions}

SRDM performed most of the experiments, analysed and interpreted the data, and wrote the first manuscript draft. SB, RAS, ALH performed some of the experiments and undertook some data interpretation. MTB and HB synthesised some of the LSD1 inhibitor compounds used under supervision from AG. LRD and PJD provided bespoke reagents (purified enzyme) for the in vitro LSD1 inhibition assay and assisted in its execution. SJC and GP conceived and supervised the overall project, individual experiments, data analysis and manuscript development and editing. All authors read and approved the final manuscript.

\section{Author details}

${ }^{1}$ Cancer Sciences Unit and Cancer Research UK Centre, University of Southampton, Southampton General Hospital, Somers Cancer Research Building, Mailpoint 824, Southampton SO16 6YD, UK. ${ }^{2}$ Protein Core Facility, Cancer Research UK and Experimental Cancer Medicine Centres, University of Southampton, Southampton General Hospital, Southampton SO16 6YD, UK. ${ }^{3}$ School of Pharmacy, University of East Anglia, Norwich NR4 7TJ, UK.

\section{Acknowledgements}

The authors would like to acknowledge the kind gift of the AR-V7 and AR Q640X expression plasmids from Jocelyn Ceraline, University of Strasbourg. 


\section{Competing interests}

$\mathrm{SC}$ has received research funding from AstraZeneca, Astex Pharmaceuticals, Clovis Oncology and Plexxikon, speaker fees from Novartis, Roche and Janssen-Cilag and honoraria for advisory board participation from Roche, Clovis Oncology, Bayer and Janssen-Cilag. The other authors declare that they have no competing interests.

\section{Availability of data and materials}

All data generated or analysed during this study are included in this published article and its additional information files.

\section{Consent for publication}

Not applicable.

\section{Ethics approval and consent to participate}

Not applicable.

\section{Funding}

This work was funded by research grants from Cancer Research UK (C9317) A20783) and Prostate Cancer UK (PG12-03).

\section{Publisher's Note}

Springer Nature remains neutral with regard to jurisdictional claims in published maps and institutional affiliations.

Received: 26 February 2018 Accepted: 30 April 2018 Published online: 09 May 2018

\section{References}

1. Niraula S, Tannock IF. Broadening horizons in medical management of prostate cancer. Acta Oncol. 2011;50(Suppl 1):141-7.

2. Beer TM, Armstrong AJ, Rathkopf DE, Loriot Y, Sternberg CN, Higano CS, Iversen P, Bhattacharya S, Carles J, Chowdhury S, et al. Enzalutamide in metastatic prostate cancer before chemotherapy. N Engl J Med. 2014;371(5):424-33.

3. de Bono JS, Logothetis CJ, Molina A, Fizazi K, North S, Chu L, Chi KN, Jones RJ, Goodman OB Jr, Saad F, et al. Abiraterone and increased survival in metastatic prostate cancer. N Engl J Med. 2011;364(21):1995-2005.

4. Ryan CJ, Smith MR, de Bono JS, Molina A, Logothetis CJ, de Souza P, Fizazi K, Mainwaring P, Piulats JM, Ng S, et al. Abiraterone in metastatic prostate cancer without previous chemotherapy. N Engl J Med. 2013;368(2):138-48

5. Scher HI, Fizazi K, Saad F, Taplin ME, Sternberg CN, Miller K, de Wit R, Mulders P, Chi KN, Shore ND, et al. Increased survival with enzalutamide in prostate cancer after chemotherapy. N Engl J Med. 2012;367(13):1187-97.

6. Kaarbo M, Klokk TI, Saatcioglu F. Androgen signaling and its interactions with other signaling pathways in prostate cancer. BioEssays. 2007;29(12):1227-38.

7. Antonarakis ES, Lu C, Wang H, Luber B, Nakazawa M, Roeser JC, Chen Y, Mohammad TA, Chen Y, Fedor HL, et al. AR-V7 and resistance to enzalutamide and abiraterone in prostate cancer. N Engl J Med. 2014;371(11):1028-38.

8. Antonarakis ES, Lu C, Luber B, Wang H, Chen Y, Zhu Y, Silberstein JL, Taylor MN, Maughan BL, Denmeade SR, et al. Clinical significance of androgen receptor splice variant-7 mRNA detection in circulating tumor cells of men with metastatic castration-resistant prostate cancer treated with first- and second-line abiraterone and enzalutamide. J Clin Oncol. 2017;35(19):2149-56.

9. Attard G, Richards J, de Bono JS. New strategies in metastatic prostate cancer: targeting the androgen receptor signaling pathway. Clin Cancer Res. 2011;17(7):1649-57.

10. Claessens F, Helsen C, Prekovic S, Van den Broeck T, Spans L, Van Poppel H, Joniau S. Emerging mechanisms of enzalutamide resistance in prostate cancer. Nat Rev Urol. 2014;11(12):712-6.

11. Nakazawa M, Antonarakis ES, Luo J. Androgen receptor splice variants in the era of enzalutamide and abiraterone. Horm Cancer. 2014;5(5):265-73.

12. Shafi AA, Yen AE, Weigel NL. Androgen receptors in hormone-dependent and castration-resistant prostate cancer. Pharm Ther. 2013;140(3):223-38.
13. Vlachostergios PJ, Puca L, Beltran $\mathrm{H}$. Emerging variants of castrationresistant prostate cancer. Curr Oncol Rep. 2017;19(5):32.

14. Metzger E, Wissmann M, Yin N, Muller JM, Schneider R, Peters AH, Gunther T, Buettner R, Schule R. LSD1 demethylates repressive histone marks to promote androgen-receptor-dependent transcription. Nature. 2005;437(7057):436-9.

15. Wissmann M, Yin N, Muller JM, Greschik H, Fodor BD, Jenuwein T, Vogler C, Schneider R, Gunther T, Buettner R, et al. Cooperative demethylation by JMJD2C and LSD1 promotes androgen receptor-dependent gene expression. Nature Cell Biol. 2007;9(3):347-53.

16. Shi YJ, Matson C, Lan F, Iwase S, Baba T, Shi Y. Regulation of LSD1 histone demethylase activity by its associated factors. Mol Cell. 2005;19(6):857-64.

17. Shi Y, Lan F, Matson C, Mulligan P, Whetstine JR, Cole PA, Casero RA, Shi Y. Histone demethylation mediated by the nuclear amine oxidase homolog LSD1. Cell. 2004;119(7):941-53.

18. Metzger E, Imhof A, Patel D, Kahl P, Hoffmeyer K, Friedrichs N, Muller JM, Greschik H, Kirfel J, Ji S, et al. Phosphorylation of histone H3T6 by PKCbeta(I) controls demethylation at histone H3K4. Nature. 2010;464(7289):792-6.

19. Laurent B, Ruitu L, Murn J, Hempel K, Ferrao R, Xiang Y, Liu S, Garcia BA, Wu H, Wu F, et al. A Specific LSD1/KDM1A isoform regulates neuronal differentiation through H3K9 demethylation. Mol Cell. 2015;57:957-70.

20. Kahl P, Gullotti L, Heukamp LC, Wolf S, Friedrichs N, Vorreuther R, Solleder G, Bastian PJ, Ellinger J, Metzger E, et al. Androgen receptor coactivators lysine-specific histone demethylase 1 and four and a half LIM domain protein 2 predict risk of prostate cancer recurrence. Cancer Res. 2006:66(23):11341-7.

21. Wang M, Liu X, Jiang G, Chen H, Guo J, Weng X. Relationship between LSD1 expression and E-cadherin expression in prostate cancer. Int Urol Nephrol. 2015;47(3):485-90.

22. Ellinger J, Kahl P, von der Gathen J, Rogenhofer S, Heukamp LC, Gutgemann I, Walter B, Hofstadter F, Buttner R, Muller SC, et al. Global levels of histone modifications predict prostate cancer recurrence. Prostate. 2010;70(1):61-9.

23. Cai $\mathrm{C}, \mathrm{He} \mathrm{HH}$, Chen S, Coleman I, Wang H, Fang Z, Chen S, Nelson PS, Liu XS, Brown M, et al. Androgen receptor gene expression in prostate cancer is directly suppressed by the androgen receptor through recruitment of lysine-specific demethylase 1. Cancer Cell. 2011;20(4):457-71.

24. Cai C, He HH, Gao S, Chen S, Yu Z, Gao Y, Chen S, Chen MW, Zhang J, Ahmed M, et al. Lysine-specific demethylase 1 has dual functions as a major regulator of androgen receptor transcriptional activity. Cell Rep. 2014:9(5):1618-27.

25. Benelkebir H, Hodgkinson C, Duriez PJ, Hayden AL, Bulleid RA, Crabb SJ, Packham G, Ganesan A. Enantioselective synthesis of tranylcypromine analogues as lysine demethylase (LSD1) inhibitors. Bioorg Med Chem. 2011;19(12):3709-16.

26. Laemmli UK. Cleavage of structural proteins during the assembly of the head of bacteriophage T4. Nature. 1970;227(5259):680-5.

27. Packham G, Brimmell M, Cleveland JL. Mammalian cells express two differently localized Bag-1 isoforms generated by alternative translation initiation. Biochem J. 1997;328:807-13.

28. Ran FA, Hsu PD, Wright J, Agarwala V, Scott DA, Zhang F. Genome engineering using the CRISPR-Cas9 system. Nat Protoc. 2013:8(11):2281-308.

29. Cottard F, Asmane I, Erdmann E, Bergerat JP, Kurtz JE, Ceraline J. Constitutively active androgen receptor variants upregulate expression of mesenchymal markers in prostate cancer cells. PLoS ONE. 2013;8(5):e63466.

30. Crabb SJ, Hague A, Johnson PW, Packham G. BAG-1 inhibits PPARgammainduced cell death, but not PPARgamma-induced transcription, cell cycle arrest or differentiation in breast cancer cells. Oncol Rep. 2008;19(3):689-96.

31. Livak KJ, Schmittgen TD. Analysis of relative gene expression data using real-time quantitative PCR and the 2(-Delta Delta C(T)) method. Methods. 2001;25(4):402-8.

32. Rathkopf DE, Morris MJ, Fox JJ, Danila DC, Slovin SF, Hager JH, Rix PJ, Chow Maneval E, Chen I, Gonen M, et al. Phase I study of ARN-509, a novel antiandrogen, in the treatment of castration-resistant prostate cancer. J Clin Oncol. 2013;31(28):3525-30.

33. Smith MR, Saad F, Chowdhury S, Oudard S, Hadaschik BA, Graff JN, Olmos D, Mainwaring PN, Lee JY, Uemura H, et al. Apalutamide Treatment and Metastasis-free Survival in Prostate Cancer. N Engl J Med. 2018:378:1408-18. 
34. Hornberg E, Ylitalo EB, Crnalic S, Antti H, Stattin P, Widmark A, Bergh A, Wikstrom P. Expression of androgen receptor splice variants in prostate cancer bone metastases is associated with castration-resistance and short survival. PLoS ONE. 2011;6(4):e19059.

35. de Bono JS, Oudard S, Ozguroglu M, Hansen S, Machiels JP, Kocak I, Gravis G, Bodrogi I, Mackenzie MJ, Shen L, et al. Prednisone plus cabazitaxel or mitoxantrone for metastatic castration-resistant prostate cancer progressing after docetaxel treatment: a randomised open-label trial. Lancet. 2010;376(9747):1147-54.
36. Kantoff PW, Higano CS, Shore ND, Berger ER, Small EJ, Penson DF, Redfern $\mathrm{CH}$, Ferrari AC, Dreicer R, Sims RB, et al. Sipuleucel-T immunotherapy for castration-resistant prostate cancer. N Engl J Med. 2010;363(5):411-22.

37. Parker C, Nilsson S, Heinrich D, Helle SI, O'Sullivan JM, Fossa SD, Chodacki A, Wiechno P, Logue J, Seke M, et al. Alpha emitter radium-223 and survival in metastatic prostate cancer. N Engl J Med. 2013;369(3):213-23.

38. Graca I, Pereira-Silva E, Henrique R, Packham G, Crabb SJ, Jeronimo C. Epigenetic modulators as therapeutic targets in prostate cancer. Clin Epigenetics. 2016;8:98.
Ready to submit your research? Choose BMC and benefit from:

- fast, convenient online submission

- thorough peer review by experienced researchers in your field

- rapid publication on acceptance

- support for research data, including large and complex data types

- gold Open Access which fosters wider collaboration and increased citations

- maximum visibility for your research: over $100 \mathrm{M}$ website views per year

At BMC, research is always in progress.

Learn more biomedcentral.com/submissions 